\title{
Cooperative Effect of Li Content and Equal-Channel Angular Pressing on Microstructure and Mechanical Properties of Al-Mg-Li Alloy
}

\author{
Ting Yuan ${ }^{1,2}$, Jinghua Jiang ${ }^{1, *}$, Yuna $\mathrm{Wu}^{1}$, Zhipeng Yuan ${ }^{3}$, Aibin Ma ${ }^{1,4}$ and Yuchun Yuan ${ }^{1}$ \\ College of Mechanics and Materials, Hohai University, Nanjing 210098, China \\ 2 School of Chemistry and Materials Engineering, Changshu Institute of Technology, Changshu 215500, China \\ 3 School of Materials Science and Engineering, Southeast University, Nanjing 211189, China \\ 4 Suqian Institute, Hohai University, Suqian 223800, China \\ * Correspondence: jinghua-jiang@hhu.edu.cn; Tel.: +86-25-8378-7239
}

Received: 25 June 2019; Accepted: 28 July 2019; Published: 29 July 2019

check for updates

\begin{abstract}
This paper investigated the cooperative effects of Li addition and warm Equal Channel Angular Pressing (ECAP) on improving the mechanical properties of an Al-Mg-Li alloy for further weight reduction. The results showed that more Li addition could obviously refine the grains of the as-cast alloy and reduce its density value to only $2.37 \mathrm{~g} / \mathrm{cm}^{3}$ when Li content reached $2.5 \%$ (about $12.6 \%$ lighter than commercial $\mathrm{Al}$ alloys). It also had a pronounced influence on the precipitations in the $\mathrm{Al}-5.5 \mathrm{Mg}-\mathrm{xLi}-0.1 \mathrm{Zr}$ alloy, i.e., the number density and size of $\mathrm{Al}_{2} \mathrm{MgLi}$ and $\delta^{\prime}-\mathrm{Al}_{3} \mathrm{Li}$ phases. The yield strength of the as-cast alloy was increased with increasing $\mathrm{Li}$, but the elongation deteriorated due to primary network intergranular $\mathrm{Al}_{2} \mathrm{MgLi}$ and more $\delta^{\prime}$ particles in the high Li-containing alloy. The warm multi-pass ECAP process was found to simultaneously improve the strength and ductility of the Al-Mg-Li alloys, and greatly alleviate the detrimental effect of Li addition on the elongation, thereby making the ultrafine-grained (UFG) alloys, a good combination of lightweight and high performance, very attractive for aerospace applications for much higher specific strength than both $\mathrm{Al}$ matrix composites and $\mathrm{Mg}$ alloys.
\end{abstract}

Keywords: equal-channel angular pressing (ECAP); Li content; Al-Mg-Li alloy; microstructures; mechanical properties

\section{Introduction}

Since weight reduction has been considered as a more and more important contributor to performance and operating cost associated with fuel efficiency, the strength/weight ratio has become the prime driver for designers to select materials for aerospace systems [1]. Under such circumstances, aluminum-lithium alloys, with lower density, higher strength, and better stiffness than conventional aluminum alloys, are considered as promising structure materials to reduce cost in the aerospace industry [2,3]. It is well known that Al-Mg-Li alloys, as one of the industrially used categories of Al-Li alloys, have the lowest densities available for a commercial aluminum alloy. Therefore, it attracts specific interest in applications that have ever-increasing demands of being light-weight, weldability, and corrosion resistance, but require only moderate strength.

The significant weight reduction effect of $\mathrm{Al}-\mathrm{Mg}-\mathrm{Li}$ alloys is associated with the addition of Lithium ( $\mathrm{Li}$ ) and Magnesium (Mg). It has been reported that $\mathrm{Mg}$ contributes to the strength of $\mathrm{Al}$ alloys mainly by solid-solution strengthening. In Al-Li alloys, $\mathrm{Mg}$ addition also reduces in the solid solubility of $\mathrm{Li}$ to facilitate the precipitation of fine $\delta^{\prime}-\mathrm{Al}_{3} \mathrm{Li}$ phases and possibly incorporates into the $\delta^{\prime}$ itself [4]. High $\mathrm{Mg}$ contents ( $>4 \mathrm{wt} \%$ ) tend to favor the formation of the equilibrium cubic phase 
$\mathrm{Al}_{2} \mathrm{MgLi}$, which normally precipitates along the grain boundaries (GBs) [5-7]. As the lightest metal, $\mathrm{Li}\left(0.5 \mathrm{~g} / \mathrm{cm}^{3}\right)$ has been well known to give the greatest weight reduction effect on $\mathrm{Al}\left(2.7 \mathrm{~g} / \mathrm{cm}^{3}\right)$. As reported, each weight percent of lithium into $\mathrm{Al}$ alloys lowers approximately $3 \%$ of density and simultaneously increases $6 \%$ of modulus [8]. It is widely accepted that the main strengthening in binary $\mathrm{Al}-\mathrm{Li}$ alloys and $\mathrm{Al}-\mathrm{Mg}-\mathrm{Li}$ alloys is generally derived from the large volume fraction of the metastable, coherent, and ordered precipitates $\left(\delta^{\prime}-\mathrm{Al}_{3} \mathrm{Li}\right.$ phase) with a $\mathrm{LI}_{2}\left(\mathrm{Cu}_{3} \mathrm{Au}\right)$ type superlattice structure. $\delta^{\prime}$ is precipitated homogeneously in the form of spherical particles, which is the main reason for high elastic modulus observed in these alloys [9]. Therefore, Li addition provides a very promising way to develop excellent light-weight $\mathrm{Al}$ alloys. Nevertheless, previous works rarely investigated the Al-Li alloys with more $\mathrm{Li}$ content. This is probably because the $\delta^{\prime}-\mathrm{Al}_{3} \mathrm{Li}$ phase contributes not only to the high value of strength and elastic modulus, but also to the low ductility and poor fracture toughness due to planar slip. $\delta$ ' phases are known to be easily sheared by dislocations, attributed to their comparatively small interfacial energy (about $10-250 \mathrm{~mJ} / \mathrm{m}^{2}$ ) and low antiphase boundary energy $\left(180 \mathrm{~mJ} / \mathrm{m}^{2}\right)$ resulting in strain localization during deformation [10].

In the past few decades, there have been many attempts at solving the problem. One approach to alleviate stress concentrations is to decrease the dislocation glide distance by the refinement of the grain size. Severe plastic deformation (SPD) has shown high effectiveness in improving the mechanical properties of $\mathrm{Al}$ alloys by greatly refined microstructure [11-13]. Among the commonly used SPD processes, equal-channel-angular pressing (ECAP) is widely considered as one of the most effective methods to produce bulk ultrafine-grained (UFG) structures without changing the initial shape of billets, and it is applicable to nearly all commercial alloys [14-16]. Lu et al. [17], for example, reported that a Mg-Gd-Zn-Zr alloy achieved refined microstructure after warm multi-pass ECAP, with simultaneously improved strength, ductility, and good plastic formability. Semenova et al. [15] demonstrated that the ultrafine-grained structure and high-angle misorientations in a Grade 5 Ti alloy processed by ECAP might contribute to the increase of ductility. As for aluminum alloys, Shokuhfar et al. [18] have found a unique combination of high strength and good impact toughness in 6061 Al alloy after ECAP process. Also, Muñoz-Morris et al. [19] improved strength while retaining reasonable ductility of an Al-Cu-Li alloy by carefully controlling the speed, temperature, and induced strain of ECAP.

Although a large number of investigations on the strengthening mechanism of aluminum and $\mathrm{Al}-\mathrm{Li}$ alloys during conventional ECAP are available, little is known about the cooperative effect between the high addition of Li element in Al-Mg-Li alloys and the ECAP process. Based on our earlier work [20], the ECAP process could decrease stress concentration and restrain crack propagation by refining the microstructure in Al-Li alloys. Therefore, warm multi-pass ECAP was expected herein to mitigate the harmful effects of $\mathrm{Li}$ addition so as to obtain a good combination of lightweight and high performance in the Al-Li alloy. In this paper, the cooperative effect of the Li content and the ECAP process on the microstructure and mechanical behavior of an Al-Mg-xLi-Zr alloy was systematically studied.

\section{Materials and Methods}

\subsection{Sample Preparation}

Al-5.5Mg-xLi-0.1Zr alloys were prepared from $99.9 \%$ pure $\mathrm{Al}, 99.9 \%$ pure $\mathrm{Mg}$, master alloys of $\mathrm{Al}-10 \% \mathrm{Zr}$ and $\mathrm{Al}-5 \% \mathrm{Li}$ through an electric resistance furnace under the protection of an Ar atmosphere. The materials were loaded in a graphite crucible and then melted at $750-780{ }^{\circ} \mathrm{C}$. LiCl-LiF mixture flux was used on the surface for protecting the melt when adding pure $\mathrm{Mg}$ and the Al-Li master alloy. Before casting, the melt was degassed by $0.6 \% \mathrm{C}_{2} \mathrm{Cl}_{6}$ and then was isothermally held at $720{ }^{\circ} \mathrm{C}$ for about $8-15 \mathrm{~min}$. The melt was finally poured into a pre-heated metallic mold. The actual chemical compositions of the Al-5.5Mg-xLi-0.1Zr alloys measured by PE Optima8000 (PerkinElmer, Waltham, MA, USA) inductively coupled plasma atomic emission spectrometry (ICP-AES) were listed in Table 1. These alloys were hereafter designated as $1.6 \mathrm{Li}, 2.0 \mathrm{Li}$, and $2.5 \mathrm{Li}$ samples, respectively. Billets with a 
dimension of $19.5 \mathrm{~mm} \times 19.5 \mathrm{~mm} \times 45 \mathrm{~mm}$ cut from the as-cast alloys were heat-treated at $500{ }^{\circ} \mathrm{C}$ for $24 \mathrm{~h}$ and quenched in water. A rotational die ECAP (RD-ECAP) setup with a channel angle of $90^{\circ}$ was applied to process 16 passes of ECAP. More details of the RD-ECAP process have been illustrated in ref. [21]. Before the ECAP process, the billets were preheated at $300{ }^{\circ} \mathrm{C}$ for $20 \mathrm{~min}$ together with the die. During the ECAP process, the average press speed was kept at $5 \mathrm{~mm} / \mathrm{min}$. Finally, the ECAPed billets were removed from the die quickly and cooled in water.

Table 1. Measured chemical compositions of Al-5.5Mg-xLi-0.1Zr (in wt $\%$ ) alloys.

\begin{tabular}{ccccccc}
\hline Al-5.5Mg-xLi-0.1Zr alloy & $\mathbf{M g}$ & $\mathbf{L i}$ & $\mathbf{Z r}$ & $\mathbf{S i}$ & $\mathbf{F e}$ & $\mathbf{A l}$ \\
\hline $1.6 \mathrm{Li}$ & 5.51 & 1.62 & 0.11 & 0.24 & 0.17 & Balance \\
$2.0 \mathrm{Li}$ & 5.85 & 1.95 & 0.11 & 0.28 & 0.11 & Balance \\
$2.5 \mathrm{Li}$ & 5.64 & 2.52 & 0.14 & 0.27 & 0.15 & Balance \\
\hline
\end{tabular}

\subsection{Microstructure Observation}

Microstructures and precipitate morphologies of the as-cast and as-pressed samples were observed by the optical microscopy (OM, Olympus BX51, Tokyo, Japan), scanning electron microscope (SEM, Hitachi-S3400N, Tokyo, Japan) with energy dispersive spectroscope (EDS) and transmission electron microscopy (TEM, FEI Tecnai G2 T20, Hillsboro, OR, USA). X-ray diffraction (XRD, D8 Advance, Karlsruhe, Germany) analyses were also used to investigate the phase existing in the as-cast samples with different Li content. The alloy density $\left(\mathrm{g} / \mathrm{cm}^{3}\right)$ was measured using the standard Archimedes method with distilled water [22]. All the samples for observation were cut along the pressing direction. The samples for OM and SEM were polished and etched with a $0.5 \%$ hydrofluoric acid solution. Samples for TEM were prepared by mechanically polishing to $\sim 60 \mu \mathrm{m}$ and subsequently, ion thinning. To characterize the initial grain size, the as-cast samples were investigated under polarized light after anodized by Barker's reagent ( $5 \mathrm{~mL} \mathrm{HBF}_{4}$ in $\left.200 \mathrm{~mL} \mathrm{H}_{2} \mathrm{O}, 25 \mathrm{~V}\right)$. Differential Scanning Calorimetry (DSC, NETZSCH SAT 449F3, Selb, Germany) was performed on the as-cast 1.6Li alloy, employing a constant heating rate of $10{ }^{\circ} \mathrm{C} / \mathrm{min}$ within the temperature range $100{ }^{\circ} \mathrm{C}-500{ }^{\circ} \mathrm{C}$.

\subsection{Testing of Mechanical Properties}

Tensile tests were carried out for all the samples at room temperature using a universal testing machine (UTM-4000, SUNS, Ningbo, China). The strain rate utilized was $5 \times 10^{-4} \mathrm{~s}^{-1}$. Dog-bone shaped tensile specimens were cut from the central regions of the ECAPed billets parallel to the longitudinal axis, with a gauge length of $8 \mathrm{~mm}$, a thickness of $2 \mathrm{~mm}$, and a width of $2 \mathrm{~mm}$.

\section{Results}

\subsection{Microstructures of As-Cast Al-5.5Mg-xLi-0.1Zr Alloy}

The phase constitutions in the as-cast Al-5.5Mg-xLi-0.1Zr alloys are exhibited in Figure 1. It can be seen that all the samples consist of $\alpha-\mathrm{Al}, \delta^{\prime}-\mathrm{Al}_{3} \mathrm{Li}$, and $\mathrm{S}_{1}-\mathrm{Al}_{2} \mathrm{MgLi}$ phases. According to the literature $[23,24]$, the intermetallic phase $\delta^{\prime}-\mathrm{Al}_{3} \mathrm{Li}$ exist in all the as-cast alloys, owing to the decomposition of $\alpha$-Al supersaturated solid solution during solidification. With the increase of Li addition, the peaks of $\delta^{\prime}$ phase at $23^{\circ}(100)$ and $32^{\circ}(110)$ become more obvious [25]. According to [26], in an Al-Mg-Li alloy containing a $\mathrm{Mg}$ content $>5 \%$ wt and a Li content $>1.7 \mathrm{wt} \%$, both the $\mathrm{S}_{1}-\mathrm{Al}_{2} \mathrm{MgLi}$ and $\delta$-AlLi phases are formed. 


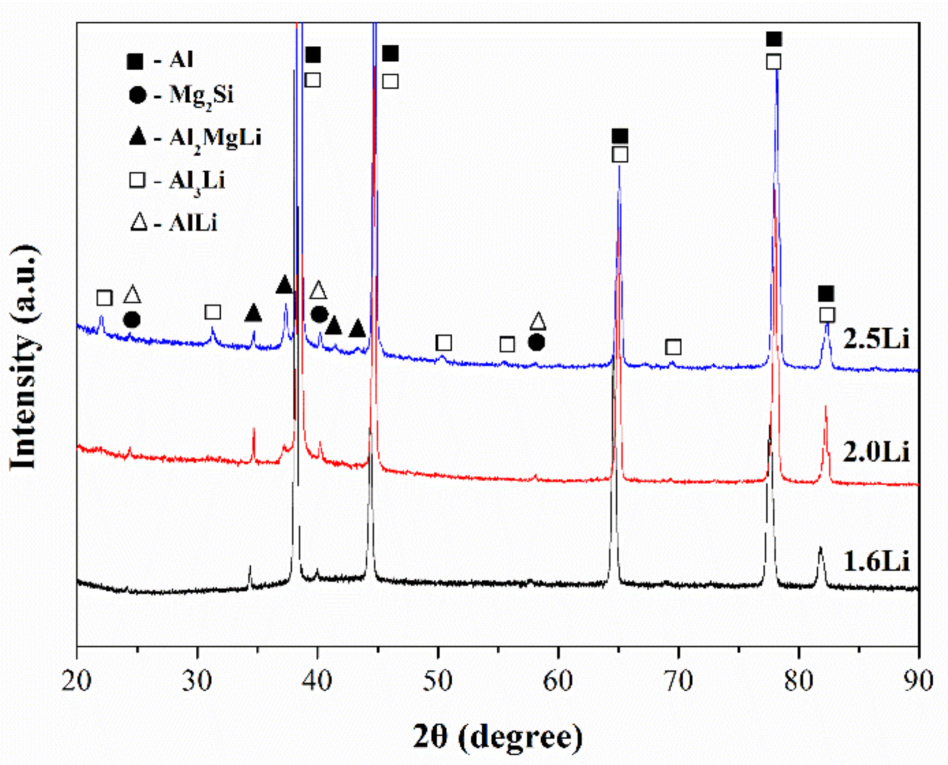

Figure 1. X-ray Diffraction (XRD) results of as-cast Al-5.5Mg-xLi-0.1Zr alloys.

Figure 2 displays the optical microstructure $(\mathrm{OM})$ and corresponding polarized light structures of the as-cast Al-5.5Mg-xLi-0.1Zr alloys. It can be seen that the as-cast alloys consisted mainly of dendritic $\alpha$-Al matrix with rod-like or network-like intermetallic compounds along the grain boundaries (indicated by white arrows). As shown in Figure 3, the EDS analysis suggest that these intergranular compounds contain as high as $20 \mathrm{wt} \%$ of $\mathrm{Mg}$ is $\mathrm{Al}_{2} \mathrm{MgLi}$ phase. Some black phases with coarse size and skeleton structure at the junction of boundaries (indicated by red arrows in Figure 2) were identified as $\mathrm{Mg}_{2} \mathrm{Si}$, which is ascribed to the small quantity of $\mathrm{Si}$ introduced from the raw materials $[5,27,28]$. The two different phases are distributed in such a way that the $\mathrm{Mg}_{2} \mathrm{Si}$ phase, which appears black either completely or incompletely, surrounds the grains of the $\mathrm{Al}_{2} \mathrm{MgLi}$ phase, which appears light-grey. This may be connected with the so-called complete and incomplete wetting of grain boundaries by the melt or by the second solid phase in alloys [29]. The wetting of Al/Al GBs by the second solid phase such as $\mathrm{Al}_{3} \mathrm{Mg}_{2}$ has been observed in Al-Mg alloys, and the transition from incomplete to complete wetting of $\mathrm{Al} / \mathrm{Al}$ GBs $[30,31]$. More attention will be paid on this phenomenon in our future research.

Compared with the microstructure of 1.6Li in our previous work (Figure 2a,d) [32], the amount of $\mathrm{Al}_{2} \mathrm{MgLi}$ phases increases apparently with the increase of Li contents, eventually leading to a continuous network of intermetallic compounds around the grains in the 2.5 Li alloy. Furthermore, the as-cast grains are obviously refined to about $87 \mu \mathrm{m}$ for $2.5 \mathrm{Li}$ alloy compared to the large grain size of $\sim 135 \mu \mathrm{m}$ for 1.6Li alloy (as shown in Figure 2d-f), which indicates that Li content has an obvious grain refinement effect on the Al-Mg-Li alloys. A similar finding was also reported by Adamczyk-Cieślak et al. [33], in which an increase of the Li content could enhance the SPD-induced microstructure refinement of binary Al-Li alloys. 


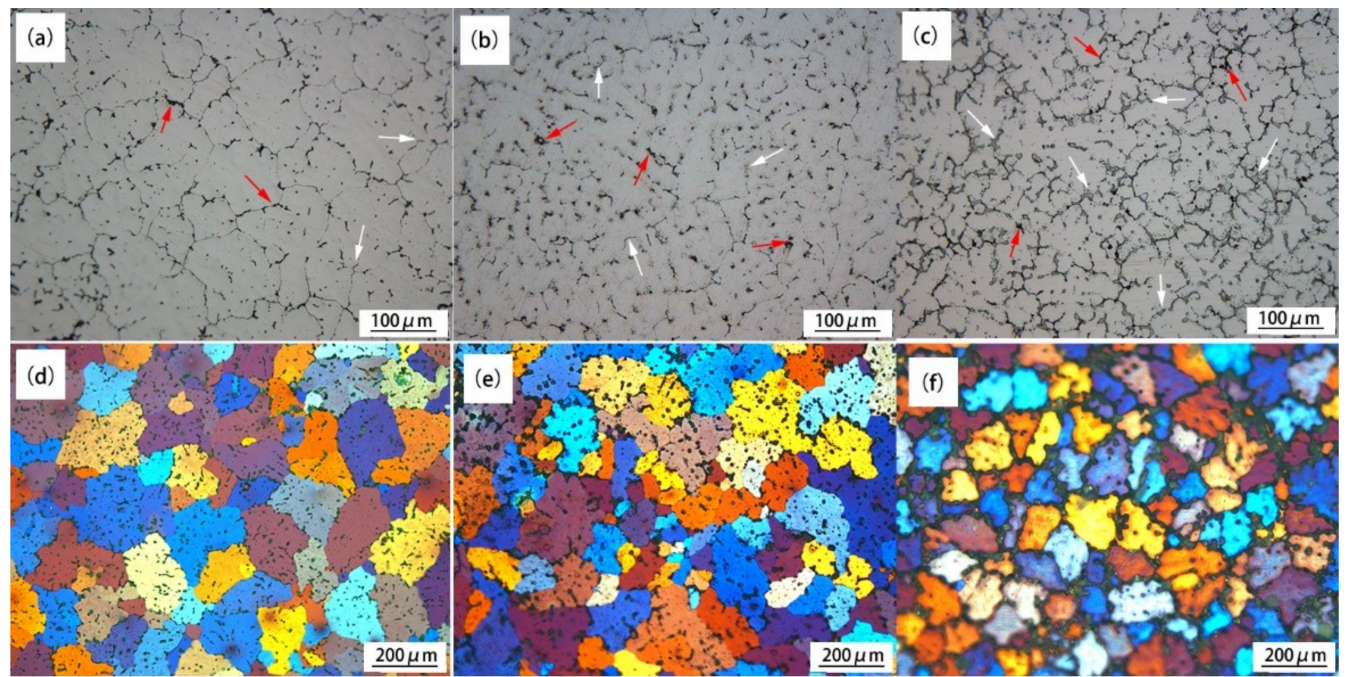

Figure 2. Optical microstructure (OM) and polarized light images of as-cast Al-5.5Mg-xLi-0.1Zr (wt $\%$ ) alloy with different Li contents: (a,d) $1.6 \mathrm{wt} \%,(\mathbf{b}, \mathbf{e}) 2.0 \mathrm{wt} \%,(\mathbf{c}, \mathbf{f}) 2.5 \mathrm{wt} \%$.
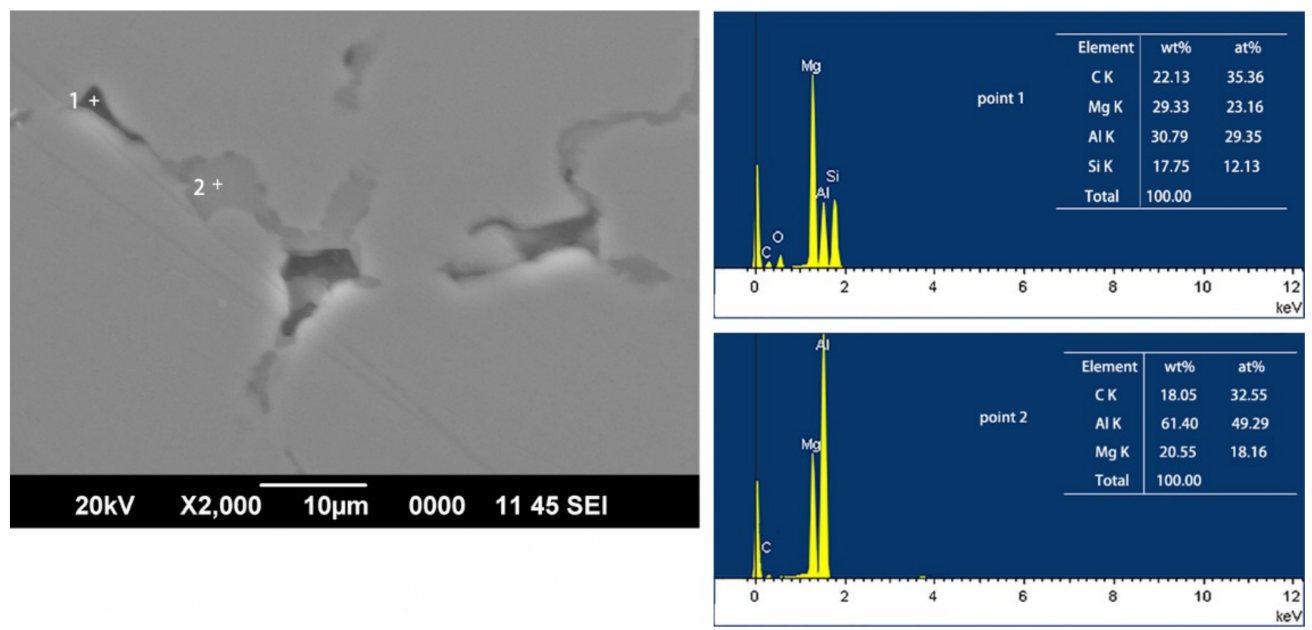

Figure 3. Energy dispersive spectroscope (EDS) results of point 1 and point 2 in the as-cast $2.5 \mathrm{Li}$ alloy.

Figure 4 illustrates the TEM dark-field images of the as-cast alloys. It presents that a high number density of spherical $\delta^{\prime}$ precipitates are uniformly distributed throughout the $\alpha$-Al matrix in the as-cast alloys. This is due to the small lattice misfit (about $0.08-0.3 \%$ ) and the low surface energy $\left(30 \mathrm{~mJ} / \mathrm{m}^{2}\right)$ of $\delta^{\prime}-\mathrm{Al}_{3} \mathrm{Li}$ relative to the $\alpha$-Al matrix, leading to a low thermodynamic nucleation barrier for $\delta^{\prime}$ to homogeneous decomposition from the matrix during solidification [34-36]. As expected, $\delta^{\prime}$ superlattice diffraction spots appear between the Al diffraction spots in the inset selected-area-diffraction (SAD) pattern taken from these areas, which is more and more apparent with increasing Li addition. The $\delta^{\prime}$-phase particles have an $\mathrm{LI}_{2}$ cubic structure $(\alpha=0.4 \mathrm{~nm})$ with an orientation relationship (OR) $(100) \delta^{\prime} / /(100) \mathrm{Al},[100] \delta^{\prime} / /[100] \mathrm{Al}$ with the Al matrix [22,37]. As the Li content increases, the $\delta^{\prime}$ phases become more and denser in the $2.0 \mathrm{Li}$ alloy, but obviously coarsen and scattered in the $2.5 \mathrm{Li}$ alloy. 


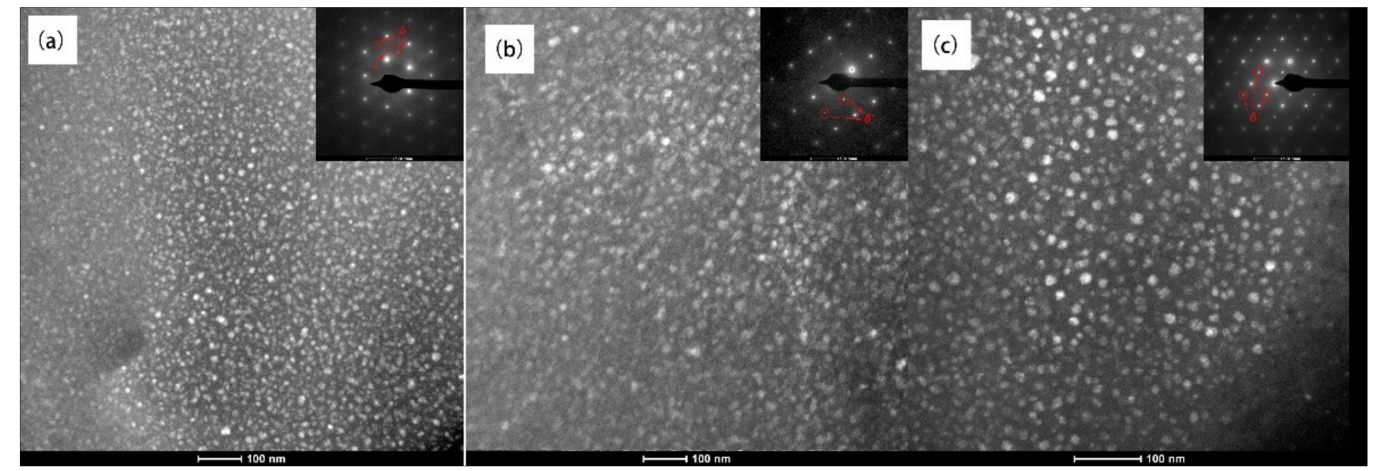

Figure 4. Transmission electron microscopy (TEM) dark-field micrographs of Al-5.5Mg-xLi- $0.1 \mathrm{Zr}(\mathrm{wt} \%)$ alloy with different Li content: (a) $1.6 \mathrm{wt} \%$; (b) $2.0 \mathrm{wt} \%$; (c) $2.5 \mathrm{wt} \%$, showing dense distribution of $\delta^{\prime}$ phases in the as-cast alloys.

The addition of lithium has the greatest effect on the density of the alloy. Figure 5 exhibits the density change of Al-Mg-Li alloys with different Li content. Among three studied Al-Mg-Li alloys, 1.6Li alloy had the highest density value $\left(2.52 \mathrm{~g} / \mathrm{cm}^{3}\right)$, but still much lower than the commercial third-generation Al-Li alloys $\left(2.63 \sim 2.72 \mathrm{~g} / \mathrm{cm}^{3}\right)$ [4]. With increasing Li content, a very low density of $2.37 \mathrm{~g} / \mathrm{cm}^{3}$ could be achieved in the $2.5 \mathrm{Li}$ alloy, which has reduced its density by $12 \%$ compared with the commercial $\mathrm{Al}$ alloy. Therefore, Li content had a significant effect on the weight reduction of $\mathrm{Al}$ alloys, which could meet the increasing demand for weight-critical components in the aerospace field.

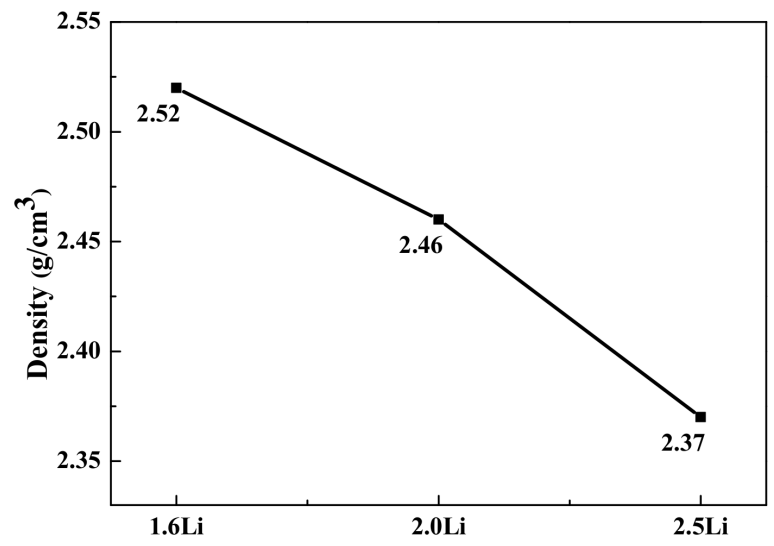

Figure 5. Density values of as-cast Al-5.5Mg-xLi-0.1Zr alloys.

\subsection{Microstructures of ECAP 16-pass Al-5.5Mg-xLi-0.1Zr Alloy}

Figure 6 displays the scanning electron micrographs (SEM) of 1.6Li, 2.0Li, and 2.5Li alloy subjected to 16 passes of ECAP at $300{ }^{\circ} \mathrm{C}$, respectively. After severe plastic deformation, the alloys with different $\mathrm{Li}$ content have similar microstructure. The dissolved $\mathrm{Al}_{2} \mathrm{MgLi}$ precipitations during heat treatment are precipitated again during ECAP process, with small size and uniform distribution. Some of the $\mathrm{Mg}_{2} \mathrm{Si}$ phases can still be found after ECAP 16 passes, but are much refined compared with those in the as-cast alloys. The TEM images of the ECAP 16-pass alloys are given in Figure 7 to gain more details of the microstructure. Similar to the early reports [20,38,39], ECAPed Al-Mg-Li-Zr alloys are characterized by ultrafine-grained structure (with grain size of $\sim 1 \mu \mathrm{m}$ ), relatively low density of dislocations, a lot of $\mathrm{Al}_{2} \mathrm{MgLi}$ particles, but few $\delta^{\prime}$ phases. Therefore, apart from the volume and number, the density of the $\mathrm{Al}_{2} \mathrm{MgLi}$ precipitations gradually increase with increasing Li content (as shown by red arrows in Figures 6 and $7 \mathrm{a}-\mathrm{c}$.), there is little difference between the microstructure of as-pressed alloys with different $\mathrm{Li}$ addition. That is to say, ECAP reduces the effect of $\mathrm{Li}$ content on the microstructure of Al-Mg-Li-Zr alloys. 


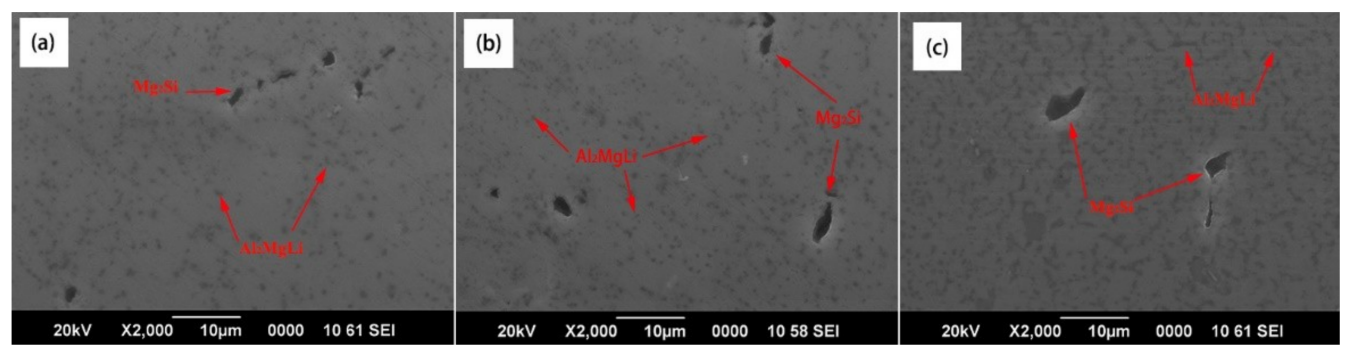

Figure 6. SEM images of equal-channel-angular pressing (ECAP) 16-pass Al-5.5Mg-xLi-0.1Zr (wt\%) alloy with different Li contents: (a) $1.6 \mathrm{wt} \%$, (b) $2.0 \mathrm{wt} \%$, (c) $2.5 \mathrm{wt} \%$.

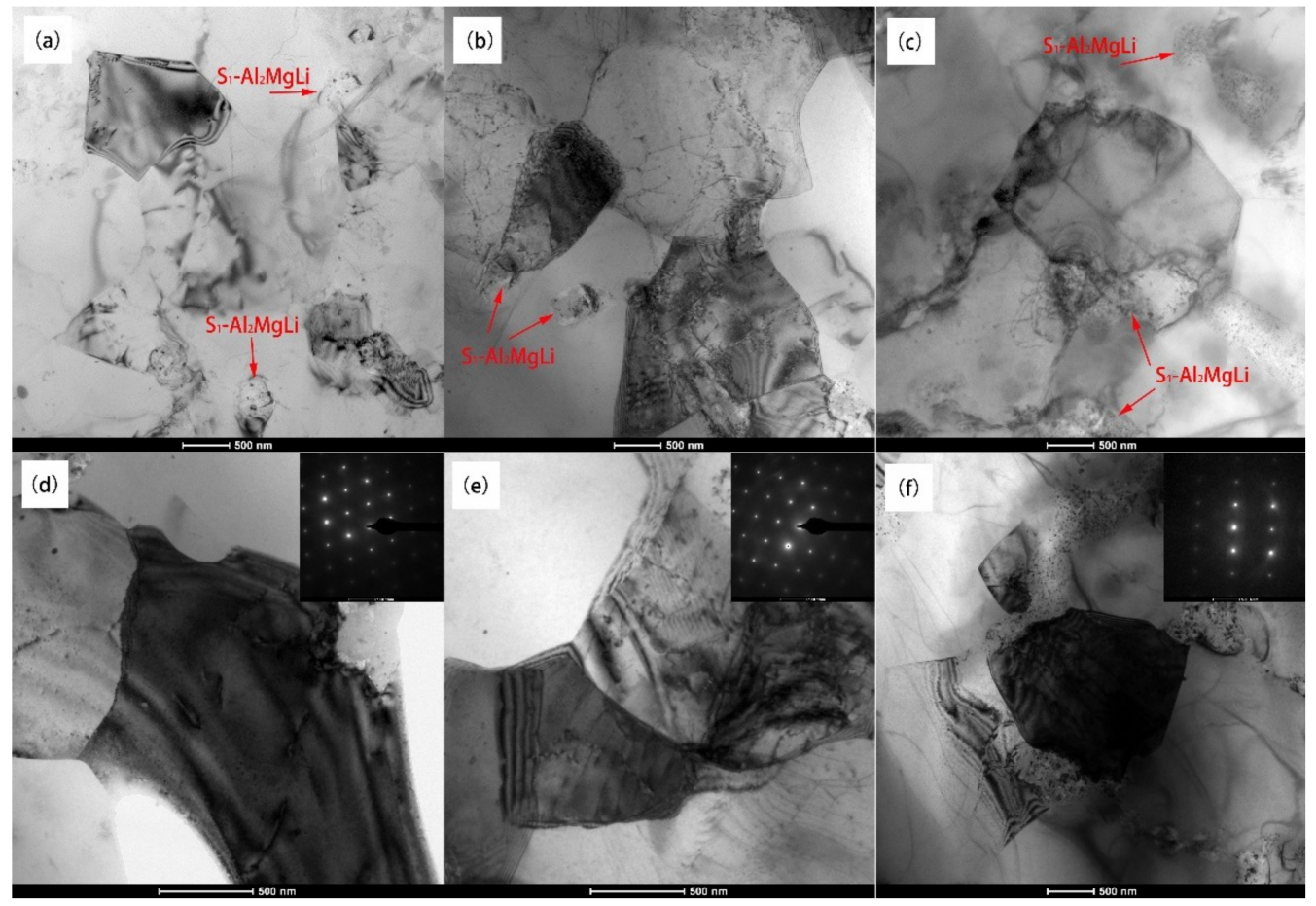

Figure 7. TEM images of ECAP 16-pass Al-5.5Mg-xLi-0.1Zr (wt\%) alloy with different Li contents: (a,d) $1.6 \mathrm{wt} \%$, (b,e) $2.0 \mathrm{wt} \%,(\mathbf{c}, \mathbf{f}) 2.5 \mathrm{wt} \%$.

\subsection{Mechanical Properties of Al-5.5Mg-xLi-0.1Zr Alloys}

The mechanical properties and typical true stress-strain curves of Al-5.5Mg-xLi-0.1Zr alloys under different states are given in Figure 8. As shown in Figure 8a, the yield strength (YS) increases almost linearly with the gradual increase of Li content, whether in the as-cast alloys or in the ECAP processed alloys. As expected, the elongation (EL) decreases a lot with Li addition. This can be attributed to the enhanced precipitation in the Al-5.5Mg-xLi-0.1Zr alloy with increasing Li content. Although multiplied precipitations of $\mathrm{Al}_{2} \mathrm{MgLi}$ and $\delta^{\prime}$ phase are beneficial to the modules and yield strength, they are detrimental to the plastic deformation ability of Al-Li alloys. Especially for the 2.5Li alloy, it manifests total brittle behavior in the as-cast state, which fractures immediately after the yield stage, as shown in Figure 8d. As a result, this great decrease in elongation with more Li addition results in dropped ultimate strength (UTS) (Figure 8b). 

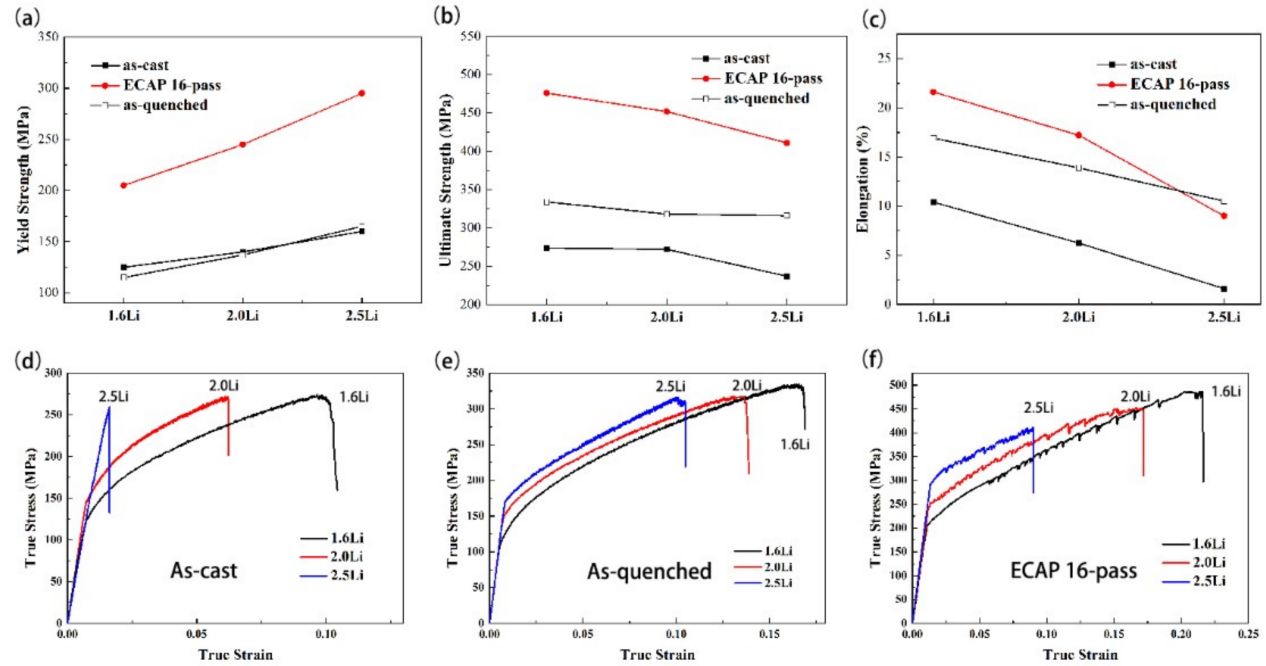

Figure 8. Mechanical properties of Al-5.5Mg-xLi-0.1Zr alloys: Comparison of (a) yield strength (YS), (b) ultimate strength (UTS) and (c) elongation (EL) of the studied alloys under different states; Stress-strain curves of the studied alloys under different states involving (d) as-cast, (e) as-quenched and (f) ECAP for 16 passes.

Generally, in the as-quenched state, the UTS and EL show an obvious improvement compared with the as-cast state, while the YS reveals little change. After processing by 16-pass ECAP, both the YS and UTS of all the samples are increased further by more than $100 \mathrm{MPa}$. Meanwhile, the EL also increases or maintains. Take the 2.5Li alloy for example, it shows obvious plastic deformation and enhanced work-hardening ability after 16-pass ECAP, the YS, UTS, and EL of which is $84 \%, 73 \%$, and $463 \%$ higher than those of the as-cast one, respectively (Figure $8 \mathrm{f}$ ), indicating a transition from brittleness to toughness. Consequently, the brittle $2.5 \mathrm{Li}$ alloy is successfully fabricated into an Al-Li alloy exhibiting a good combination of strength $(>410 \mathrm{MPa})$ and ductility $(\approx 10 \%)$. This fact indicates that the harmful effect of high Li content on the mechanical properties of as-cast alloys could be greatly reduced by warm multi-pass ECAP process. That is to say, the warm multi-pass ECAP greatly contributes to both strength and elongation enhancement, making the fabrication of ultralight UFG Al-Li alloys with good mechanical properties possible [40-42].

Specific strength, defined as the ratio of ultimate strength to density of materials, is an important parameter in the design of light-weight structures, especially for aerospace applications. Figure 9 presents the specific strength of the current studied alloys after ECAP 16 passes and some other typical light materials [43-46]. It is well known that within light-weight materials, the biggest competitors of aluminum alloys are composite materials and magnesium alloys. Magnesium alloys, especially Mg-Li alloys, are well known for their extremely low density and high specific strength, so as to be highlighted as excellent potential candidates for lightweight structures. As shown in Figure 9, the investigated alloys possess much higher specific strength compared to that of the pure $\mathrm{Al}$, aluminum matrix composite, and $\mathrm{Mg}$-Li alloys. Besides, $\mathrm{Al}-\mathrm{Li}$ alloys not only require much lower cost for the manufacturing and maintenance than composites but also exhibit higher corrosion resistance and better elongation compared with $\mathrm{Mg}$ and $\mathrm{Mg}-\mathrm{Li}$ alloys. Consequently, the result puts forward great prospects for ECAPed Al-Li alloys in the aerospace field due to their lightweight and high specific strength characteristics. 


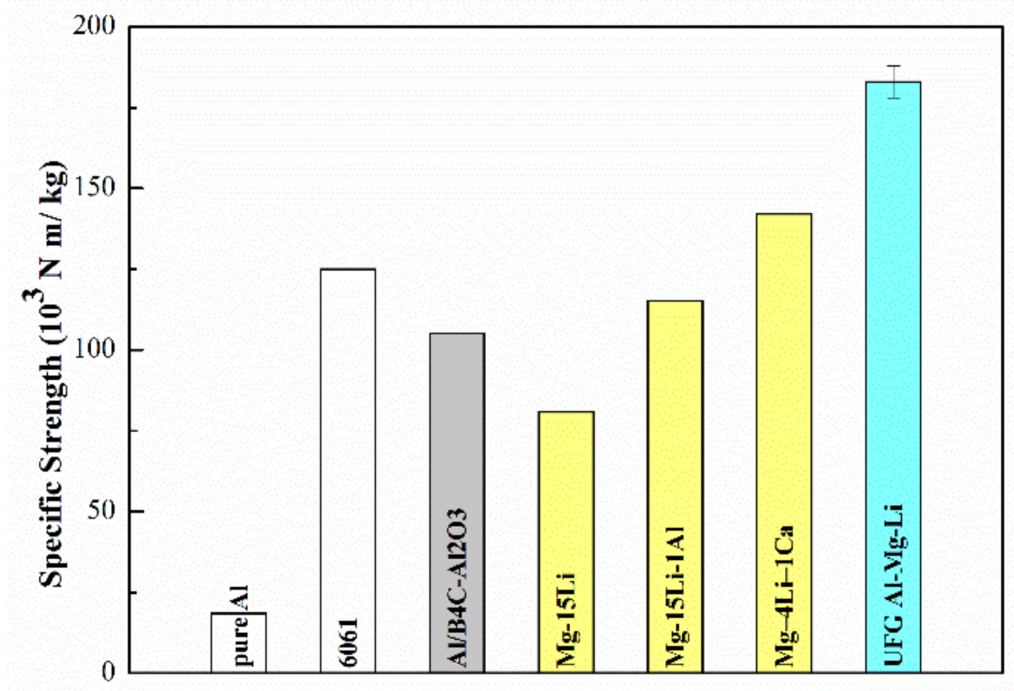

Figure 9. Specific fracture strength of ECAPed Al-5.5Mg-xLi-0.1Zr alloy and other types of materials.

\subsection{Fracture Surface Observation}

After tensile testing at room temperature, the fractured surfaces of the studied alloys with different Li content were observed by SEM. The typical fracture morphology with and without ECAP process are presented in Figure 10. The fracture surfaces of the as-cast samples (Figure 10a,c,e) reveal a predominantly quasi-cleavage fracture mode, in which tearing ridges, cleavage planes, and steps may be distinguished. According to the earlier report [47], intergranular compounds could offer potential sites for stress concentration and facilitate the formation and extension of microcracks. Thereafter, fracture would happen along the interface between the phases and the $\alpha$-Al matrix, where the cleavage planes can be observed (indicated by white arrows). Moreover, it is well accepted that the coherent $\delta^{\prime}-\mathrm{Al}_{3} \mathrm{Li}$ particle is expected to provide a possible fracture path due to planar slip. As a result, these primary phases bring about low elongation, which is consistent with the mechanical properties of the as-cast alloys (Figure 8). With increased Li content, more intergranular intermetallic compounds appeared in the as-cast alloys, as previously shown in Figure 2. Therefore, the strain localization caused by the intergranular phases and the shearing of $\delta^{\prime}$ particles will be intensified, leading to a sharply decreased ductility in the as-cast alloys. This is also demonstrated by more intermetallic compounds on the fracture surface (shown by red circles in Figure 10e) and the occurrence of both cleavage plans and grain boundaries, which is the fracture features of combined quasi-cleavage mode with intergranular mode.

After subjected to 16-pass ECAP, as shown in Figure 10b,d,f, a dimple-dominant fracture feature with a great number of dimples appeared on the fracture surface, which indicated a more ductile fracture mode comparing with the as-cast state. These dimples in the as-pressed alloys are the result of void growth and coalescence. During mechanical loading, disintegration between refined precipitates and $\alpha$-Al matrix give rise to the nucleation of voids, which would gradually grow and coalesce at the precipitates [48]. As a consequence, the remarkable microstructural change by severe plastic deformation, mainly the homogeneously distributed and greatly refined precipitations, dissolution of $\delta^{\prime}$ phases and ultrafine-grained microstructure, contributes to the transformation from brittle cleavage fracture to ductile dimple fracture after ECAP, thus significantly improving the ductility of the Li-containing alloys. However, in the as-pressed 2.5 Li alloy as shown in Figure 10f, the dimples become sparser and shallower, accompanied by the appearance of small grain boundaries, revealing a signal of the decrease of elongation. 


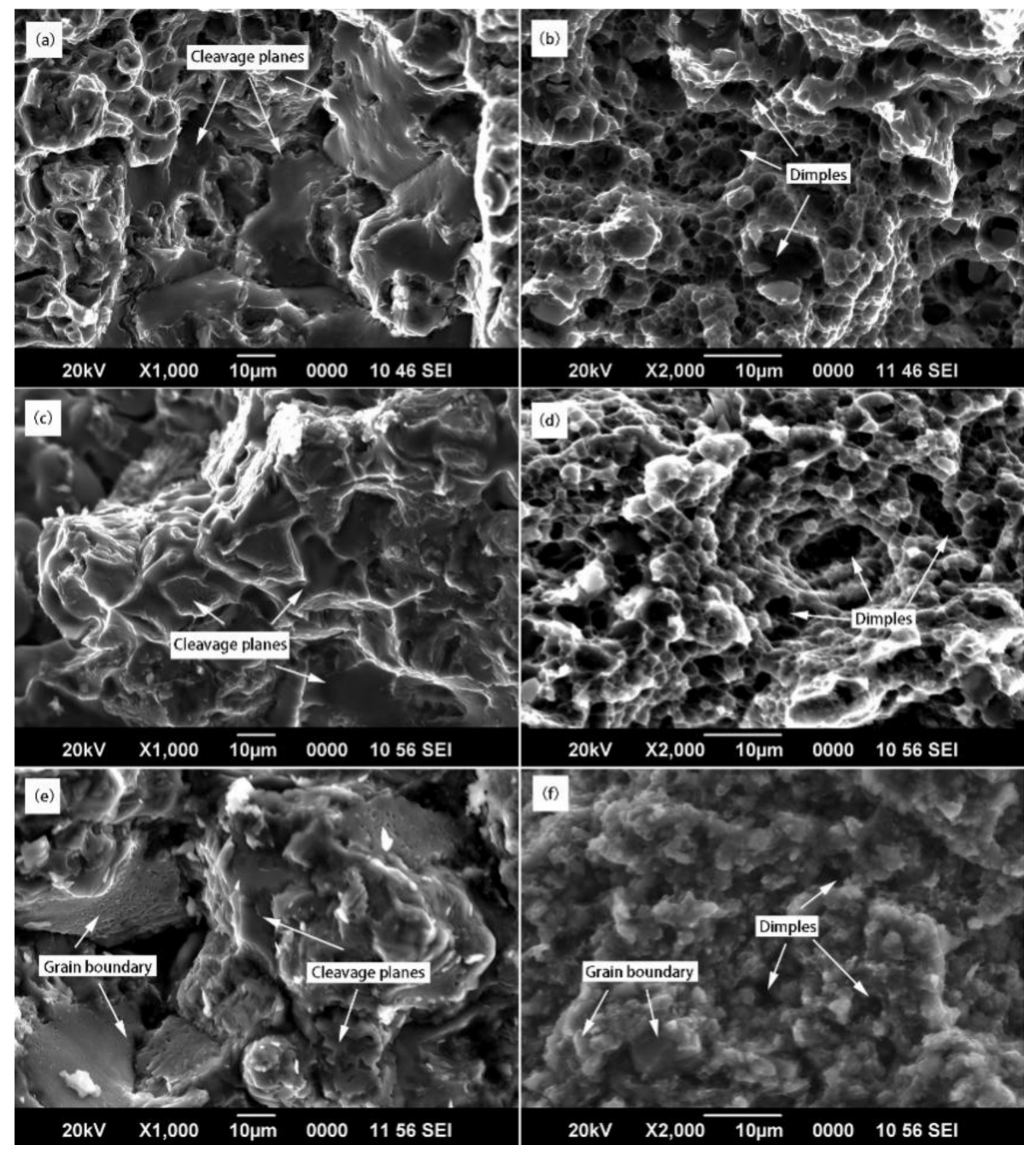

Figure 10. Fracture surfaces of as-cast $(\mathbf{a}, \mathbf{c}, \mathbf{e})$ and as-pressed $(\mathbf{b}, \mathbf{d}, \mathbf{f}) \mathrm{Al}-5.5 \mathrm{Mg}-\mathrm{xLi}-0.1 \mathrm{Zr}(\mathrm{wt} \%)$ alloy with different Li content: (a,b) $1.6 \mathrm{wt} \%$; (c,d) $2.0 \mathrm{wt} \%$; (e,f) $2.5 \mathrm{wt} \%$.

\section{Discussion}

On the basis of the above investigation, the cooperative effect of equal-channel angular pressing and $\mathrm{Li}$ content on the microstructure improvement of the Al-Mg-Li alloy is summarized in Table 2. For the as-cast alloy, Li addition has an obvious influence on the microstructure. That is, continuous network of more and coarser $\mathrm{Al}_{2} \mathrm{MgLi}$ along the boundaries, enhanced $\delta^{\prime}$ precipitations and refined grains with increased Li addition. For the ECAPed alloys, the effect of Li addition on the microstructure of Al-Mg-Li alloys is greatly weakened by severe plastic deformation. The microstructure of alloys with different $\mathrm{Li}$ content has similar features. The only difference is that the $\mathrm{Al}_{2} \mathrm{MgLi}$ precipitated during ECAP are more and coarser in the high Li-containing alloy than those in the low Li-containing alloy. 
Table 2. Summary of the main features of the microstructure in the Al-5.5Mg-xLi-0.1Zr alloy at different states.

\begin{tabular}{ccc}
\hline \multirow{2}{*}{ State } & \multicolumn{2}{c}{ Al-5.5Mg-xLi-0.1Zr } \\
\cline { 2 - 3 } & low Li addition & High Li addition \\
\hline \multirow{2}{*}{ As-cast } & Rod-like $\mathrm{Al}_{2} \mathrm{MgLi}$ and Coarse $\mathrm{Mg}_{2} \mathrm{Si}$ at & Continuous network of more and \\
& grain boundaries; & coarser $\mathrm{Al}_{2} \mathrm{MgLi} ;$ \\
& Large amount of $\delta^{\prime}$ in the matrix; & Enhanced $\delta^{\prime}$ precipitation; \\
Coarse grain size. & Refined grains. \\
\hline \multirow{2}{*}{ ECAP 16-pass } & Dispersed $\mathrm{Al}_{2} \mathrm{MgLi}$ precipitates; & Prompted $\mathrm{Al}_{2} \mathrm{MgLi}_{\text {precipitations; }}$ \\
& Lack of $\delta^{\prime} ;$ & Lack of $\delta^{\prime} ;$ \\
& Ultrafine grains. & Ultrafine grains.
\end{tabular}

It is well known that the main intermetallic phases in the Al-Mg-Li alloys are $\delta^{\prime}\left(\mathrm{Al}_{3} \mathrm{Li}\right)$ and $\mathrm{S}_{1}\left(\mathrm{Al}_{2} \mathrm{MgLi}\right)$. Researches on precipitation in such alloys are mainly focused on the dominated precipitation of the metastable $\delta^{\prime}$ phase after classical aging treatment. The ternary phase $S_{1}-\mathrm{Al}_{2} \mathrm{MgLi}$ only tend to take over the $\delta^{\prime}$ phase at high temperatures and long aging times [5]. But in our work, $\mathrm{S}_{1}$ phase plays a more and more important role with increasing Li content. According to the quantitative analysis by S. Betsofen and M. Chizhikov [49], the phase ratio of the two main intermetallic phases $\delta^{\prime}$ and $S_{1}$ phases can be calculated by the following balance equations.

$$
\begin{aligned}
& 100 X_{A l}^{0}=X_{A l}^{\alpha} W_{\alpha}+X_{A l}^{S_{1}} W_{S_{1}}+X_{A l}^{\delta^{\prime}} W_{\delta^{\prime}} \\
& 100 X_{M g}^{0}=X_{M g}^{\alpha} W_{\alpha}+X_{A l}^{S_{1}} W_{S_{1}} \\
& 100 X_{L i}^{0}=X_{L i}^{\alpha} W_{\alpha}+X_{L i}^{S_{1}} W_{S_{1}}+X_{L i}^{\delta^{\prime}} W_{\delta^{\prime}} \\
& W_{\alpha}+W_{S_{1}}+W_{\delta \prime}=100
\end{aligned}
$$

where $X_{A l^{\prime}}^{0}, X_{A l^{\prime}}^{\alpha}, X_{A l^{\prime}}^{S_{1}}, X_{A l^{\prime}}^{\delta \prime} X_{M g^{\prime}}^{0}, X_{M g^{\prime}}^{\alpha} X_{M g^{\prime}}^{S_{1}} X_{L i^{\prime}}^{0}, X_{L i^{\prime}}^{\alpha}, X_{L i}^{S_{1}}$, and $X_{L i}^{\delta \prime}$ are the $\mathrm{Al}, \mathrm{Mg}$ and Li contents in the alloy, $\alpha-A l, S_{1}$ and $\delta^{\prime}(\%)$ phases, respectively. And $W_{\alpha}, W_{S_{1}}$ and $W_{\delta}$, represent the mass fractions of the $\alpha, S_{1}$ and $\delta^{\prime}(\%)$ in the alloy, respectively. The values of $X_{A l^{\prime}}^{S_{1}} X_{A l^{\prime}}^{\delta^{\prime}}, X_{M g^{\prime}}^{S_{1}} X_{L i}^{S_{1}}$, and $X_{L i}^{\delta \prime}$ are given in the reference [49]. We employ the value of $X_{M g}^{0}$ in our work as 5.5 and the substitution $X_{A l}^{0}=100-X_{M g}^{0}-X_{L i}^{0}$, the solution indicating the relationship between the mass fraction of the phases with Li content in the alloy from the set of equation (1) can be obtained.

$$
\begin{aligned}
& W_{\delta \prime}=96.6-1.08 X_{L i}^{0}-0.01\left(X_{A l}^{\alpha}-X_{M g}^{\alpha}\right) W_{\alpha} \\
& W_{S_{1}}=40.8 X_{L i}^{0}-304+\left(0.03 X_{A l}^{\alpha}-0.37 X_{M g}^{\alpha}\right) W_{\alpha}
\end{aligned}
$$

Although $X_{A l^{\prime}}^{\alpha}, X_{M g^{\prime}}^{\alpha}$ and $W_{\alpha}$ are unknown here, they have very small impact. From the solution, it can be found that Li content has a great effect on the mass fraction of $S_{1}$ phase but has a much smaller effect on the mass fraction of $\delta^{\prime}$. It is well consistent with our observation through OM, SEM, and TEM images. With the increasing $\mathrm{Li}$ addition, much more and coarser $\mathrm{Al}_{2} \mathrm{MgLi}$ phases can be observed in whether as-cast or as-pressed alloys.

After ECAP, the presence of $\mathrm{S}_{1}-\mathrm{Al}_{2} \mathrm{MgLi}$ particles can even hinder the precipitation of $\delta^{\prime}$ phase. This phenomenon can be interpreted by the Differential Scanning Calorimetry (DSC) result of 1.6Li alloy exhibited in Figure 11. There are three endothermic peaks, " $A$ ", " $B$ ", and " $C$ ", at the temperature interval $160-200{ }^{\circ} \mathrm{C}, 350-370{ }^{\circ} \mathrm{C}$ and $420-440{ }^{\circ} \mathrm{C}$, respectively. The first endothermic peak, " $\mathrm{A}$ ", is related to the dissolution of $\delta^{\prime}$-particles, which already existed in the as-cast state [50]. The second and third endothermic peaks " $\mathrm{B}$ " and " $\mathrm{C}$ " are ascribed to the dissolution of the precipitation of $\mathrm{S}_{1}-\mathrm{Al}_{2} \mathrm{MgLi}$. In [51], the $S_{1}$-phase can be identified as two kinds differing from their crystal lattice character, with different dissolution temperature range. Davydov et al. [6] also found that the decomposition with $\mathrm{S}_{1}$-phase in temperature interval $250-375{ }^{\circ} \mathrm{C}$ begins with minimal used duration $(15 \mathrm{~s})$, and the 
formation of $\delta^{\prime}$-phase at the interval $100-200{ }^{\circ} \mathrm{C}$. During the heat treatment at $500{ }^{\circ} \mathrm{C}$ in our works, the $\mathrm{S}_{1}$ phases can be absolutely dissolved. After that, ECAP is performed processed at a temperature much higher than the ranges of the existence of $\delta^{\prime}$ phases [52]. $\delta^{\prime}$ phases dissolve, while greatly refined grains and large strains induced by ECAP bring about a lot of (sub)grain boundaries and a certain number of dislocations, which provides a large number of heterogeneous precipitation sites for $\mathrm{S}_{1}-\mathrm{Al}_{2} \mathrm{MgLi}$ phases. So, a lot of $\mathrm{S}_{1}$-phases precipitates from the matrix during ECAP, which consume most of the Li content, leading to a low driving force for the precipitation of $\delta^{\prime}$ phases.

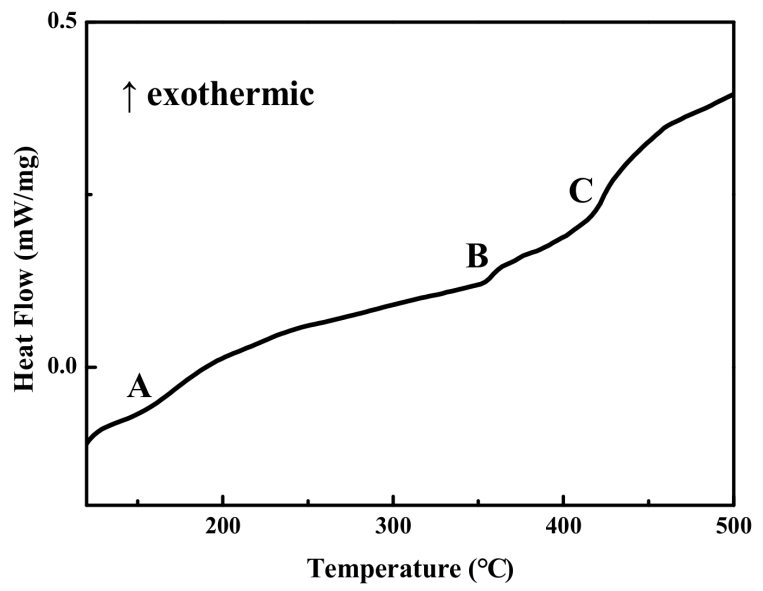

Figure 11. Differential Scanning Calorimetry (DSC) result from the as-cast 1.6Li alloy within the temperature range $100-500{ }^{\circ} \mathrm{C}$.

From the mechanical properties in Figure 8, it is found that for the as-cast alloys, every $0.5 \mathrm{wt} \%$ Li addition provides $13 \%$ and $14 \%$ increase in $\mathrm{YS}$, but $50 \%$ and $74 \%$ decrease in EL; for the ECAPed alloys, every $0.5 \mathrm{wt} \% \mathrm{Li}$ addition provides $19 \%$ and $20 \%$ increase in $\mathrm{YS}$, but $25 \%$ and $47 \%$ decrease in EL. Several things can be concluded from these data: Li addition has more influence on the mechanical properties when its content in the alloy is higher; Li has a positive effect on the strengthening of the Al-Mg-Li alloys, but makes a much more negative impact on the ductility. Last but not least, the ECAP process amplifies the positive effect, and furthermore, significantly diminishes the negative impact.

These conclusions are well related with the cooperative effect of Li addition and ECAP process on the microstructure of $\mathrm{Al}-\mathrm{Mg}-\mathrm{Li}$ alloys. In general, $\delta^{\prime}-\mathrm{Al}_{3} \mathrm{Li}$ is the main strengthening phase in the binary Al-Li alloy, and ternary Al-Mg-Li alloy, which attracts much attention in the existing researches, while $\mathrm{S}_{1}-\mathrm{Al}_{2} \mathrm{MgLi}$ phase is considered to play a less important role in the strength. This is also true in the studied as-cast alloys; enhanced precipitation of nanoscale $\delta^{\prime}-\mathrm{Al}_{3} \mathrm{Li}$ particles, with increased $\mathrm{Li}$ addition, play a major role in the increase of $Y S$. The coarse $S_{1}$-phases, present in the vicinity of grain boundaries in a strong heterogeneous manner, provided little contribution to strength. Nevertheless, both enhanced $\delta^{\prime}-\mathrm{Al}_{3} \mathrm{Li}$ and coarsen $\mathrm{S}_{1}$ phases with $\mathrm{Li}$ addition were responsible for the decrease of EL, due to planar slip and intergranular stress concentration, respectively. As a result, Li addition has a more impact on the ductility of as-cast Al-Mg-Li alloy than on its strengthening. When Li content is higher, the much more $S_{1}$-phases are tended to form network-like distribution, so as to affect the mechanical properties more.

After ECAP, the microstructure is greatly refined, with small $\mathrm{S}_{1}$ particles precipitated uniformly, and the $\delta^{\prime}-\mathrm{Al}_{3} \mathrm{Li}$ dissolved in the matrix. It is not difficult to infer that the ultrafine grains and dispersed $S_{1}$ phases after ECAP provide more than a $60 \%$ increase in YS, and more than a $110 \%$ increase in EL compared with the as-cast state. Considering that the as-pressed alloys with different Li content have similar micron-scale grains, the formation of more and coarser particles of $S_{1}$ phases in the increased Li-containing ECAPed alloys lead to the increase in YS and decrease in EL. That is because the $S_{1}$ phase precipitated during ECAP is in the form of a colony composed of several small $\mathrm{Al}_{2} \mathrm{MgLi}$ crystallites, which may hinder the operation of grain boundary dislocation sources and pin the separate dislocations 
and sub-boundaries $[51,53,54]$. Similar to the as-cast alloys, the coarsening of the phase weakens the strengthening effect, but magnifies the negative effect on ductility with increasing Li content. However, ECAP process enlarges the positive effect of $\mathrm{Li}$ addition, but significantly reduces the negative impact, which is concerned with the small size of dispersed $S_{1}$ precipitations and enhanced work-hardening ability of the matrix through severe plastic deformation.

\section{Conclusions}

The cooperative effects of $\mathrm{Li}$ addition and ECAP on the microstructure improvement and mechanical properties of $\mathrm{Al}-5.5 \mathrm{Mg}-\mathrm{xLi}-0.1 \mathrm{Zr}$ alloy have been investigated in the present study. The following conclusions can therefore be drawn:

(1) $\mathrm{Li}$ addition apparently refines the grains of the as-cast $\mathrm{Al}-5.5 \mathrm{Mg}-\mathrm{xLi}-0.1 \mathrm{Zr}$ alloy and greatly reduces the density value of the alloy. However, much more and coarser intergranular $\mathrm{Al}_{2} \mathrm{MgLi}$ phases, as well as coherent $\delta^{\prime}-\mathrm{Al}_{3} \mathrm{Li}$ particles occur in high $\mathrm{Li}$ alloys. This promotes quasi-cleavage fracture and intergranular fracture in as-cast state, thus leading to sharply decreased ductility.

(2) Warm multi-pass ECAP provides a simple and effective process for microstructure refinement and homogeneity of Al-Mg-Li alloy. The grain size is reduced to $\sim 1 \mu \mathrm{m}$, and the precipitation of $\mathrm{Al}_{2} \mathrm{MgLi}$ is prompted after 16 passes of ECAP. With increased Li addition, the alloy is characterized by growing and increased $S_{1}$ precipitations, similar ultrafine grains, low density of dislocations, and a lack of $\delta^{\prime}$ phases.

(3) Li addition reduces the elongation and ultimate strength, but increases the yield strength of the alloys in both as-cast and as-pressed state. Cooperative ECAP process could remarkably improve the tensile mechanical properties of Al-Li alloys, thus effectively eliminating the harmful effect of $\mathrm{Li}$ addition. Warm multi-pass ECAP process offers a promising way to develop excellent light-weight Al-Mg-Li alloys with much higher specific strength than Al matrix composites and Mg alloys.

Author Contributions: The work presented here was carried out in collaboration between all authors. J.J. defined the research theme; T.Y., and Z.Y. performed the main experiments; T.Y. analyzed the data and wrote the main draft of the paper; Y.W., A.M., and Y.Y. co-designed experiments, discussed the analysis, and revised the manuscript. All authors contributed to the discussion of the results and approved the manuscript.

Funding: The study was supported by the Fundamental Research Funds for the Central Universities (Grant No. 2019B79814 and 2018B48414), National Natural Science Foundation of China (Grant No. 51774109), the Key Research and Development Project of Jiangsu Province of China (Grant No.BE2017148), Postgraduate Education Reform Project of Jiangsu Province (JGLX19_027), and Science \& Technology Plan Program of Suzhou City of China (Grant No. SYG201820).

Conflicts of Interest: The authors declare no conflict of interest.

\section{References}

1. Williams, J.C.; Starke, E.A. Progress in structural materials for aerospace systems. Acta Mater. 2003, 51, 5775-5799. [CrossRef]

2. Rioja, R.J.; Liu, J. Fabrication methods to manufacture isotropic Al-Li products for space and aerospace applications. Mater. Sci. Eng. A 1998, 257, 100-107. [CrossRef]

3. Elagin, V.I.; Zakharov, V.V. Aluminium-lithium alloys. J. Mater. Sci. 1987, 22, 1521-1529.

4. Abd El-Aty, A.; Xu, Y.; Guo, X.; Zhang, S.; Ma, Y.; Chen, D. Strengthening mechanisms, deformation behavior, and anisotropic mechanical properties of Al-Li alloys: A review. J. Adv. Res. 2018, 10, 49-67. [CrossRef] [PubMed]

5. Deschamps, A.; Sigli, C.; Mourey, T.; de Geuser, F.; Lefebvre, W.; Davo, B. Experimental and modelling assessment of precipitation kinetics in an Al-Li-Mg alloy. Acta Mater. 2012, 60, 1917-1928. [CrossRef]

6. Davydov, V.G.; Ber, L.B.; Kaputkin, E.Y.; Komov, V.I.; Ukolova, O.G.; Lukina, E.A. TTP and TTT diagrams for quench sensitivity and ageing of 1424 alloy. Mater. Sci. Eng. A 2000, 280, 76-82. [CrossRef]

7. Martin, J.W. Aluminium-lithium alloys. Ann. Rev. Mater. Sci. 1988, 18, 101-119. [CrossRef] 
8. Lavernia, E.J.; Srivatsan, T.S.; Mohamed, F.A. Strength, deformation, fracture behavior and ductility of aluminium-lithium alloys. J. Mater. Sci. 1990, 25, 1137-1158. [CrossRef]

9. Ovri, H.; Lilleodden, E.T. New insights into plastic instability in precipitation strengthened Al-Li alloys. Acta Mater. 2015, 89, 88-97. [CrossRef]

10. Prasad, N.E.; Ramachandran, T.R. Phase diagrams and phase reactions in aluminum-lithium alloys. In Aluminum-lithium Alloys: Processing, Properties, and Applications; Prasad, E., Gokhale, A., Wanhill, H., Eds.; Butterworth-Heinemann: Oxford, UK, 2014; pp. 66-90.

11. Alvandi, H.; Farmanesh, K. Microstructural and mechanical properties of nano/ultra-fine structured 7075 aluminum alloy by accumulative roll-bonding process. Procedia Mater. Sci. 2015, 11, 17-23. [CrossRef]

12. Ito, Y.; Horita, Z. Microstructural evolution in pure aluminum processed by high-pressure torsion. Mater. Sci. Eng. A 2009, 503, 32-36. [CrossRef]

13. Ma, K.; Wen, H.; Hu, T.; Topping, T.D. Mechanical behavior and strengthening mechanisms in ultrafine grain precipitation-strengthened aluminum alloy. Acta Mater. 2014, 62, 141-155. [CrossRef]

14. Yuan, Y.; Ma, A.; Gou, X.; Jiang, J.; Arhin, G.; Song, D.; Liu, H. Effect of heat treatment and deformation temperature on the mechanical properties of ECAP processed ZK60 magnesium alloy. Mater. Sci. Eng. A 2016, 677, 125-132. [CrossRef]

15. Semenova, I.P.; Polyakov, A.V.; Polyakova, V.V.; Grishina, Y.F.; Huang, Y.; Valiev, R.Z.; Langdon, T.G. Mechanical behavior and impact toughness of the ultrafine-grained Grade $5 \mathrm{Ti}$ alloy processed by ECAP. Mater. Sci. Eng. A 2017, 696, 166-173. [CrossRef]

16. Zhang, L.Y.; Ma, A.B.; Jiang, J.H.; Wu, H.S.; Yu, H.B. Effect of equal-channel angular pressing passes on corrosion behavior of ultrafine-grained pure iron. Adv. Mater. Res. 2015, 1095, 942-946. [CrossRef]

17. Lu, F.; Ma, A.; Jiang, J.; Chen, J.; Song, D.; Yuan, Y.; Chen, J.; Yang, D. Enhanced mechanical properties and rolling formability of fine-grained $\mathrm{Mg}-\mathrm{Gd}-\mathrm{Zn}-\mathrm{Zr}$ alloy produced by equal-channel angular pressing. J. Alloy Compd. 2015, 643, 28-33. [CrossRef]

18. Shokuhfar, A.; Nejadseyfi, O. A comparison of the effects of severe plastic deformation and heat treatment on the tensile properties and impact toughness of aluminum alloy 6061. Mater. Sci. Eng. A 2014, 594, 140-148. [CrossRef]

19. Munoz-Morris, M.A.; Morris, M.D. Severe plastic deformation processing of Al-Cu-Li alloy for enhancing strength while maintaining ductility. Scripta Mater. 2010, 63, 304-307. [CrossRef]

20. Jiang, J.; Yuan, T.; Zhang, W.; Ma, A.; Song, D.; Wu, Y. Effect of equal-channel angular pressing and post-aging on impact toughness of Al-Li alloys. Mater. Sci. Eng. A 2018, 733, 385-392. [CrossRef]

21. Ma, A.; Suzuki, K.; Nishida, Y.; Saito, N.; Shigematsu, I.; Takagi, M.; Iwata, H.; Watazu, A.; Imura, T. Impact toughness of an ultrafine-grained $\mathrm{Al}-11 \mathrm{mass} \% \mathrm{Si}$ alloy processed by rotary-die equal-channel angular pressing. Acta Mater. 2005, 53, 211-220. [CrossRef]

22. Chen, A.; Wu, G.; Zhang, L.; Zhang, X.; Shi, C.; Li, Y. Microstructural characteristics and mechanical properties of cast Al-3Li-xCu-0.2Zr alloy. Mater. Sci. Eng. A 2016, 677, 29-40. [CrossRef]

23. Chen, A.; Zhang, L.; Wu, G.; Sun, M.; Liu, W. Influences of Mn content on the microstructures and mechanical properties of cast Al-3Li-2Cu-0.2Zr alloy. J. Alloy Compd. 2017, 715, 421-431. [CrossRef]

24. Noble, B.; Bray, S.E. On the $\alpha(\mathrm{Al}) / \delta^{\prime}\left(\mathrm{Al}_{3} \mathrm{Li}\right)$ metastable solvus in aluminum-lithium alloys. Acta Mater. 1998, 46, 6163-6171. [CrossRef]

25. Shamas, U.D.; Kamran, J.; Tariq, N.H.; Hasan, B.A.; Petrov, R.H.; Bliznuk, V.; Shamas, U.Z. The synergistic effect of $\mathrm{Li}$ addition on microstructure, texture and mechanical properties of extruded $\mathrm{Al}-\mathrm{Mg}-\mathrm{Si}$ alloys. Mater. Chem. Phys. 2016, 174, 11-22.

26. Truong, C.T.; Kabisch, O.; Gille, W.; Schmidt, U. Small angle X-ray scattering and electrical resistivity measurements on an Al-2Li-5Mg-0.1Zr alloy. Mater. Chem. Phys. 2002, 73, 268-273. [CrossRef]

27. Betsofen, S.Y.; Antipov, V.V.; Knyazev, M.I. Al-Cu-Li and Al-Mg-Li alloys: Phase composition, texture, and anisotropy of mechanical properties (review). Russ. Metall. 2016, 2016, 326-341. [CrossRef]

28. Hogg, S.C.; Palmer, I.G.; Thomas, L.G. Processing, microstructure and property aspects of a spraycast Al-Mg-Li-Zr alloy. Acta Mater. 2007, 55, 1885-1894. [CrossRef]

29. Mazilkin, A.A.; Abrosimova, G.E.; Protasova, S.G.; Straumal, B.B.; Schütz, G.; Dobatkin, S.V.; Bakai, A.S. Transmission electron microscopy investigation of boundaries between amorphous "grains" in Ni50Nb20Y30 alloy. J. Mater. Sci. 2011, 46, 4336-4342. [CrossRef] 
30. Straumal, B.B.; Kogtenkova, O.A.; Murashkin, M.Y.; Bulatov, M.F.; Czeppe, T.; Zięba, P. Grain boundary wetting transition in Al-Mg alloys. Mater. Lett. 2017, 186, 82-85. [CrossRef]

31. Straumal, B.B.; Baretzky, B.; Kogtenkova, O.A.; Straumal, A.B.; Sidorenko, A.S. Wetting of grain boundaries in $\mathrm{Al}$ by the solid Al3Mg2 phase. J. Mater. Sci. 2010, 45, 2057-2061. [CrossRef]

32. Yuan, T.; Jiang, J.; Ma, A.; Wu, Y.; Yuan, Y.; Li, C. Simultaneously improving the strength and ductility of an Al-5.5Mg-1.6Li-0.1Zr alloy via warm multi-pass ECAP. Mater. Charact. 2019, 151, 530-541. [CrossRef]

33. Adamczyk-Cieślak, B.; Mizera, J.; Kurzydłowski, K.J. Thermal stability of model Al-Li alloys after severe plastic deformation-Effect of the solute Li atoms. Mater. Sci. Eng. A 2010, 527, 4716-4722. [CrossRef]

34. Gault, B.; Cui, X.Y.; Moody, M.P.; De Geuser, F.; Sigli, C.; Ringer, S.P.; Deschamps, A. Atom probe microscopy investigation of $\mathrm{Mg}$ site occupancy within $\delta^{\prime}$ precipitates in an Al-Mg-Li alloy. Scripta Mater. 2012, 66, 903-906. [CrossRef]

35. Zhao, Z.; Lin, L.; Zheng, C. Co-strengthening contribution of $\delta^{\prime}$ and T I precipitates in Al-Li alloys 2090 and 2090 + Ce. Rare Met. 2006, 25, 197-201. [CrossRef]

36. Zhang, X.; Zhang, L.; Wu, G. Microstructural evolution and mechanical properties of cast Al-2Li-2Cu-0.5Mg-0.2Zr alloy during heat treatment. Mater. Charact. 2017, 132, 312-319. [CrossRef]

37. Wang, S.C.; Starink, M.J. Precipitates and intermetallic phases in precipitation hardening Al-Cu-Mg-(Li) based alloys. Int. Mater. Rev. 2005, 50, 193-215. [CrossRef]

38. Mogucheva, A.; Kaibyshev, R. Microstructure and mechanical properties of an Al-Li-Mg-Sc-Zr alloy subjected to ECAP. Metals 2016, 6, 254. [CrossRef]

39. Deschamps, A.; Garcia, M.; Chevy, J.; Davo, B.; De Geuser, F. Influence of Mg and Li content on the microstructure evolution of AlCuLi alloys during long-term ageing. Acta Mater. 2017, 122, 32-46. [CrossRef]

40. Lee, B.; Kim, S.; Park, J.; Kim, H.; Lee, J. Role of Mg in simultaneously improving the strength and ductility of Al-Mg alloys. Mater. Sci. Eng. A 2016, 657, 115-122. [CrossRef]

41. Zha, M.; Li, Y.; Mathiesen, R.H.; Bjørgec, R.; Rovena, H.J. Microstructure evolution and mechanical behavior of a binary Al-7Mg alloy processed by equal-channel angular pressing. Acta Mater. 2015, 84, 42-54. [CrossRef]

42. Kumar, S.; Pink, E. Serrated flow in aluminum alloys containing lithium. Acta Mater. 1997, 45, 5295-5301. [CrossRef]

43. Alizadeh, M.; Beni, H.A.; Ghaffari, M.; Amini, R. Properties of high specific strength Al- $4 \%$ wt $\mathrm{Al}_{2} \mathrm{O}_{3} / \mathrm{B}_{4} \mathrm{C}$ nano-composite produced by accumulative roll bonding process. Mater. Des. 2013, 50, 427-432. [CrossRef]

44. Park, G.H.; Kim, J.T.; Park, H.J.; Kim, Y.S.; Jeong, H.J.; Lee, N.; Seo, Y.; Suh, J.; Son, H.; Wang, W.; Park, J.M.; Kim, K.B. Development of lightweight Mg-Li-Al alloys with high specific strength. J. Alloy Compd. 2016, 680, 116-120. [CrossRef]

45. Nene, S.S.; Kashyap, B.P.; Prabhu, N.; Estrin, Y.; Al-Samman, T. Microstructure refinement and its effect on specific strength and bio-corrosion resistance in ultralight $\mathrm{Mg}-4 \mathrm{Li}-1 \mathrm{Ca}$ (LC41) alloy by hot rolling. J. Alloy Compd. 2014, 615, 501-506. [CrossRef]

46. Li, D.; Li, H.; Zhu, Z.W.; Wang, A.M.; Fu, H.M.; Zhang, H.F.; Zhang, H.W. New ductile laminate structure of Ti-alloy/Ti-based metallic glass composite with high specific strength. J. Mater. Sci. Technol. 2018, 34, 708-712. [CrossRef]

47. Peng, Y.; Chen, A.; Zhang, L.; Liu, W.; Wu, G. Effect of solution treatment on microstructure and mechanical properties of cast Al-3Li-1.5Cu-0.2Zr alloy. J. Mater. Res. 2016, 31, 1124-1132. [CrossRef]

48. Shi, C.; Zhang, L.; Wu, G.; Zhang, X.; Chen, A.; Tao, J. Effects of Sc addition on the microstructure and mechanical properties of cast Al-3Li-1.5Cu-0.15Zr alloy. Mater. Sci. Eng. A 2017, 680, 232-238. [CrossRef]

49. Betsofen, S.; Chizhikov, M. Quantitative Phase Analysis of Al-Mg-Li and Al-Cu-Li Alloys. Mater. Sci. Forum 2014, 794-796, 915-920. [CrossRef]

50. Chen, A.; Peng, Y.; Zhang, L.; Wu, G.; Li, Y. Microstructural evolution and mechanical properties of cast Al-3Li-1.5Cu-0.2Zr aloy during heat treatment. Mater. Charact. 2016, 114, 234-242. [CrossRef]

51. Naydenkin, E.V.; Ivanov, K.V. Characteristic features of structure evolution and phase composition of an ultrafine-grained Al-Mg-Li-Zr alloy produced by severe plastic deformation. Russ. Phys. J. 2014, 56, 1025-1029. [CrossRef]

52. Shneider, G.L. Phase transformations in heat treatment of Al-Li alloys and optimization of operational properties of semifinished products from these alloys. Met. Sci. Heat Treat. 1998, 40, 27-33. [CrossRef] 
53. Mazilkin, A.A.; Kamalov, M.M.; Myshlyaev, M.M. Structure and phase composition of an Al-Mg-Li-Zr alloy under high-rate superplasticity conditions. Phys. Solid State 2004, 46, 1456-1461. [CrossRef]

54. Kaibyshev, R.; Musin, F.; Saytaeva, K. Formation of ultrafine grains during intense plastic straining in an Al-Li alloy at $400{ }^{\circ} \mathrm{C}$. In Proceedings of the 2nd International Symposium on Ultrafine Grained Materials, Seattle, WA, USA, 17-21 February 2002; pp. 81-88. 